\title{
BMJ Open The work of return to work. Challenges of returning to work when you have chronic pain: a meta-ethnography
}

\author{
Mary Grant, ${ }^{1}$ Joanne O-Beirne-Elliman, ${ }^{1}$ Robert Froud, ${ }^{1,2}$ Martin Underwood, ${ }^{1}$ \\ Kate Seers ${ }^{3}$
}

To cite: Grant M, 0-BeirneElliman J, Froud R, et al. The work of return to work. Challenges of returning to work when you have chronic pain: a meta-ethnography. BMJ Open 2019;9:e025743. doi:10.1136/ bmjopen-2018-025743

- Prepublication history and additional material for this paper are available online. To view these files, please visit the journal online (http://dx.doi. org/10.1136/bmjopen-2018025743).

Received 3 August 2018 Revised 26 February 2019 Accepted 17 April 2019

Check for updates

(C) Author(s) (or their employer(s)) 2019. Re-use permitted under CC BY. Published by BMJ.

${ }^{1}$ Clinical Trials Unit, University of Warwick, Warwick Medical School, Coventry, UK

${ }^{2}$ Department of Health Sciences, Kristiania University College, Oslo, Norway

${ }^{3}$ Warwick Research in Nursing, University of Warwick, Warwick Medical School, Coventry, UK

Correspondence to

Dr Mary Grant;

M.Grant.2@warwick.ac.uk

\section{ABSTRACT}

Aims To understand obstacles to returning to work, as perceived by people with chronic non-malignant pain and as perceived by employers, and to develop a conceptual model.

Design Synthesis of qualitative research using metaethnography.

Data sources Eleven bibliographic databases from inception to April 2017 supplemented by citation tracking. Review methods We used the methods of metaethnography. We identified concepts and conceptual categories, and developed a conceptual model and line of argument.

Results We included 41 studies. We identified three core categories in the conceptual model: managing pain, managing work relationships and making workplace adjustments. All were influenced by societal expectations in relation to work, self (self-belief, self-efficacy, legitimacy, autonomy and the meaning of work for the individual), health/illness/pain representations, prereturn to work support and rehabilitation, and system factors (healthcare, workplace and social security). A mismatch of expectations between the individual with pain and the workplace contributed to a feeling of being judged and difficulties asking for help. The ability to navigate obstacles and negotiate change underpinned mastering return to work despite the pain. Where this ability was not apparent, there could be a downward spiral resulting in not working. Conclusions For people with chronic pain, and for their employers, navigating obstacles to return to work entails balancing the needs of (1) the person with chronic pain, (2) work colleagues and (3) the employing organisation. Managing pain, managing work relationships and making workplace adjustments appear to be central, but not straightforward, and require substantial effort to culminate in a successful return to work.

\section{INTRODUCTION}

Chronic pain, defined as pain lasting 3 months or more, ${ }^{1}$ is a global public health problem affecting one in ten adults. ${ }^{2}$ A 2017 mega-ethnography brought together 11 qualitative evidence syntheses to explore the experience of living with chronic non-malignant pain. ${ }^{3}$ Previous reviews have identified the importance of the effect of chronic pain on people's work life. ${ }^{45}$ Chronic pain is strongly

\section{Strengths and limitations of this study}

This is the first study to present employer and employee perspectives together.

- This study draws together what is known from qualitative studies to inform practice.

- This study highlights health and illness and pain representations in relation to return to work.

- Only five studies covered employers' perspectives, so there are fewer data on employers' perspectives compared with the perspectives of people with chronic pain.

associated with claiming disability and unemployment benefit in Australia ${ }^{1}$ and with unemployment in the USA. ${ }^{6}$ The obstacles to staying in work for people with musculoskeletal pain have previously been explored in a meta-ethnography, ${ }^{7}$ and factors promoting staying at work are the focus of a previous mixed-methods systematic review. ${ }^{8}$ A qualitative systematic review of the impact of chronic pain in the workplace ${ }^{9}$ takes a broad perspective including impact on employment status, sickness absence and loss of productivity in contrast to a condition and gender-specific literature review focused on work and rehabilitation for women with fibromyalgia. ${ }^{10}$ There is a qualitative research on the perspective of doctors, ${ }^{11}$ but this is not considered further in this paper.

The lack of focus on return to work for people with chronic non-malignant pain and the perspective of employers presents a knowledge gap in existing reviews. Return to work can refer to the process of returning after a period of sick leave ${ }^{12}$ or returning after a period of unemployment. ${ }^{13}$ This review uses qualitative evidence synthesis to increase understanding of the obstacles to return to work for people with chronic pain and their employers, and this can then inform intervention development to support return to work. $^{414}$ 


\section{METHODS}

\section{Aims and objectives}

This meta-ethnography explores experiences of returning to work, as perceived by people with chronic non-malignant pain and by employers, and develops a conceptual model.

\section{Study design}

There are two main approaches to synthesising qualitative research, one that aggregates findings to describe the literature and one that aims to interpret findings and develop a conceptual understanding. ${ }^{4}{ }^{15}$ Meta-ethnography is an interpretative form of knowledge synthesis that was chosen for this study in order to both integrate and develop a greater understanding of existing knowledge and identify any other overarching concepts that would explain the data. The seven phases of meta-ethnography are outlined by Noblit and Hare ${ }^{15}$ and elaborated on by Toye $e t a l .{ }^{14}$ These are (1) getting started by identifying the area of interest; (2) deciding what is relevant; (3) reading and rereading the studies; (4) determining how the studies are related, which involves creating a list of key phrases, ideas, metaphors and concepts; (5) translating the studies into one another, where direct comparisons are made and similar concepts are sorted into categories; (6) synthesising the translations, where researchers make sense of the conceptual categories to develop new knowledge and understanding; and (7) expressing the synthesis. A line of argument was constructed by examining how the conceptual categories relate to each other.

\section{Identifying and appraising the review articles}

Search methods

\section{Study selection}

Eleven electronic bibliographic databases were searched (Allied and Complementary Medicine (AMED); Applied Social Science Index and Abstracts (ASSIA); The Cumulative Index to Nursing and Allied Health Literature (CINAHL); EMBASE; International Bibliography of the Social Sciences (IBSS); MEDLINE; PsycINFO; Social Services Abstracts; Sociological Abstracts; Web of Science and Westlaw) from inception up until 25 April 2017, supplemented by backward and forward citation tracking using Scopus. These databases were considered appropriate because in early scoping work we identified relevant studies in these databases. An academic support librarian undertook the initial search in collaboration with RF in December 2016, and this was updated by MG in April 2017, who continued the screening and selection of papers. The search terms used included 'Chronic pain' and 'Return to work (MeSH) OR Employment OR Employer OR Supported Employment (MeSH)'. In April 2017 two additional search terms were used, 'pain' to broaden search as 'chronic pain' was not identifying all relevant papers, and 'qualitative' as suggested by Shaw et $\mathrm{ll}^{16}$ to focus the search on studies with this type of methodology. The search strategy is detailed in online supplementary file 1. All qualitative studies using face-to-face interviews and focus groups which explored perceptions of obstacles to return to work, in employers and people who were off work, sick-listed and had chronic pain, were included. Non-English-language texts were excluded.

\section{Quality appraisal}

The quality of studies was evaluated using the Critical Appraisal Skills Programme (CASP) qualitative assessment tool. ${ }^{17}$ A scoring system was used for CASP (yes=3, can't tell $=2, n o=1$ ). A score of 20 or higher indicates the paper is deemed to be of satisfactory quality. The GRADE-CERQual (Grading of Recommendations Assessment, Development and Evaluation-Confidence in the level of Evidence from Reviews of Qualitative research) approach was also completed. ${ }^{18}{ }^{19}$ Confidence in review findings was assessed based on four components: adequacy of data, ${ }^{20}$ coherence,${ }^{21}$ methodological limitations $^{22}$ and relevance. ${ }^{23}$

\section{Analysis}

Initially, the first 10 papers (in alphabetical order of author) were read by MG, KS and JO-B-E in order to identify key 'concepts', the raw data of meta-ethnography. ${ }^{14}$ These concepts are ideas drawn from the findings of the original papers. They are also known as second-order concepts because they are the authors' interpretations of the participants' narratives (known as first-order concepts). ${ }^{24}$ The participants' narratives chosen by the author are examples of second-order concepts. ${ }^{14}$ After reading these 10 papers, the concepts identified by each researcher were amalgamated through discussion and grouped into conceptual categories that the team then worked collaboratively to name. This took place over a series of three meetings. These conceptual categories are third-order concepts insofar as they are the researchers' interpretations of second-order concepts. All concepts were identified by all three authors (KS, MG, JO-B-E), and even if exact wording differed the concept was the same. This is the way that studies were translated and related to each other. The first author then proceeded to read the rest of the papers and continue this process of analysis. Five additional papers were also read by KS and JO-B-E where MG felt a collaborative discussion would be helpful due to the nature and/orfindings of the studies. Thus $25 \%$ of papers were checked $(n=10)$, then an additional $10 \%$ were checked (ie, $35 \%$ in total) to ensure ratings and concepts were in agreement. All the included papers were uploaded to QSR International's NVivo V.11 software, ${ }^{25}$ and nodes were created for the conceptual categories. The next stage was to make sense of these categories through further discussion, make decisions about which were the core categories and develop a line of argument and conceptual model, ${ }^{14}$ involving a further four meetings. Recurring and common concepts were compared across studies, ${ }^{15}$ where directly comparable (reciprocal translation) together they contributed to our line of argument. We did not find studies that stood in opposition (refutational translation). The line of argument makes a whole of something more than a sum of the parts. ${ }^{15} \mathrm{MG}$, 


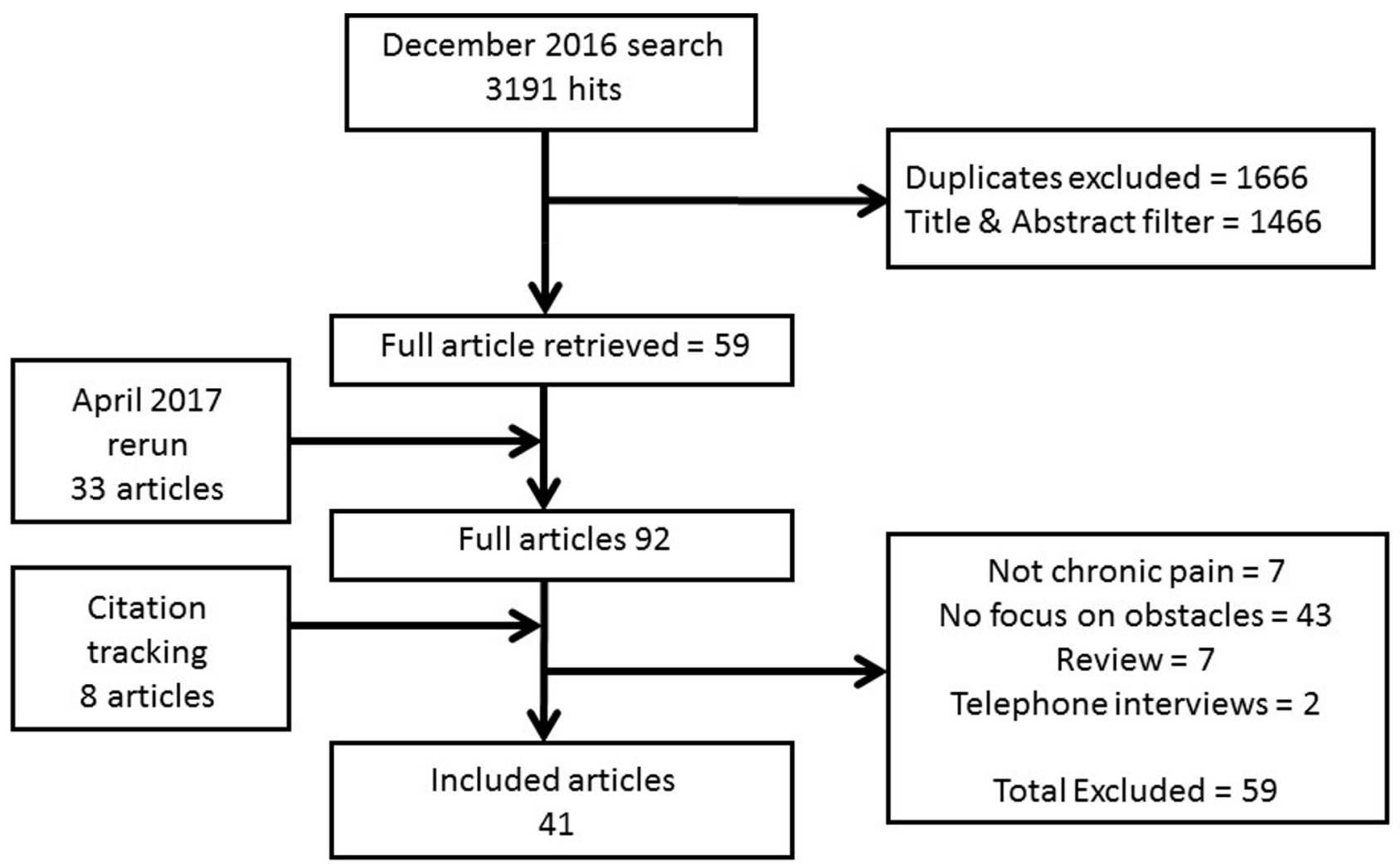

Figure 1 Flow chart illustrating search outcome.

JO-B-E and KS independently drew their own conceptual model before coming together to agree a model, which was revised through several discussions, and the final version is presented in this paper. The culture described by Toye $e t a l^{26}$ of a core team that provided a safe environment in which to freely discuss, agree, disagree and change their position in relation to conceptual analysis was seen as a key strength, laying the foundations for a rigorous review. This approach was adopted in this review. We explored alternative interpretations and explanations, including locus of control, navigating relationships, normalising participants' pain condition and agency but these ideas were not supported as major concepts. Many of these concepts were subsumed in other categories.

\section{Patient and public involvement}

A patient and public representative was involved in the development of the research funding submission for the overall study as a coapplicant and endorsed the importance of the focus of this meta-ethnography recognising the central nature of obstacles to return to work.

\section{RESULTS}

\section{Search outcome and overview of studies reviewed}

We include 41 papers and the search outcome is illustrated by a flow chart in figure 1 . The initial 3191 hits were screened by titles and abstracts, duplicates excluded, and a further 1466 were excluded at this stage. Following the reading of full texts, papers were excluded as they were neither about chronic pain nor specifically about return to work. All studies that were critically appraised passed the first two screening questions of the CASP tool that related to whether there was a clear statement of the aims of the research and if qualitative methodology was considered appropriate to address the research goal. ${ }^{17}$ CASP scores are presented in online supplementary file 2. Of the 41 articles included, 32 reported interview studies and 9 focus group studies. Twenty-one studies were from Scandinavia (14 in Sweden, 4 in Norway and 3 in Denmark), 7 were from the UK, 7 were from Canada, 2 in France, and 1 each from Australia, South Africa, Switzerland and USA. Only five studies were from the employer's perspectives. One study included in the review did not specify the type of chronic pain, but the majority of the studies involved people or employers of people with musculoskeletal pain, mainly affecting the back and neck, and some were injury/work-related. Studies of people with musculoskeletal disease, including arthritis, fibromyalgia and systemic lupus erythematosus, were also included (table 1).

\section{Overarching conceptual categories}

A total of 342 concepts were clustered into 16 conceptual categories summarised in table 2. The first column of table 2 contains third-order concepts. We worked with second-order concepts, and the second column of table 2 is second-order data, some of which are illustrated with first-order participant quotations. This table also highlights the CERQual profile. The three key conceptual categories identified by the team are described in this section. The balancing of these three inter-related categories 


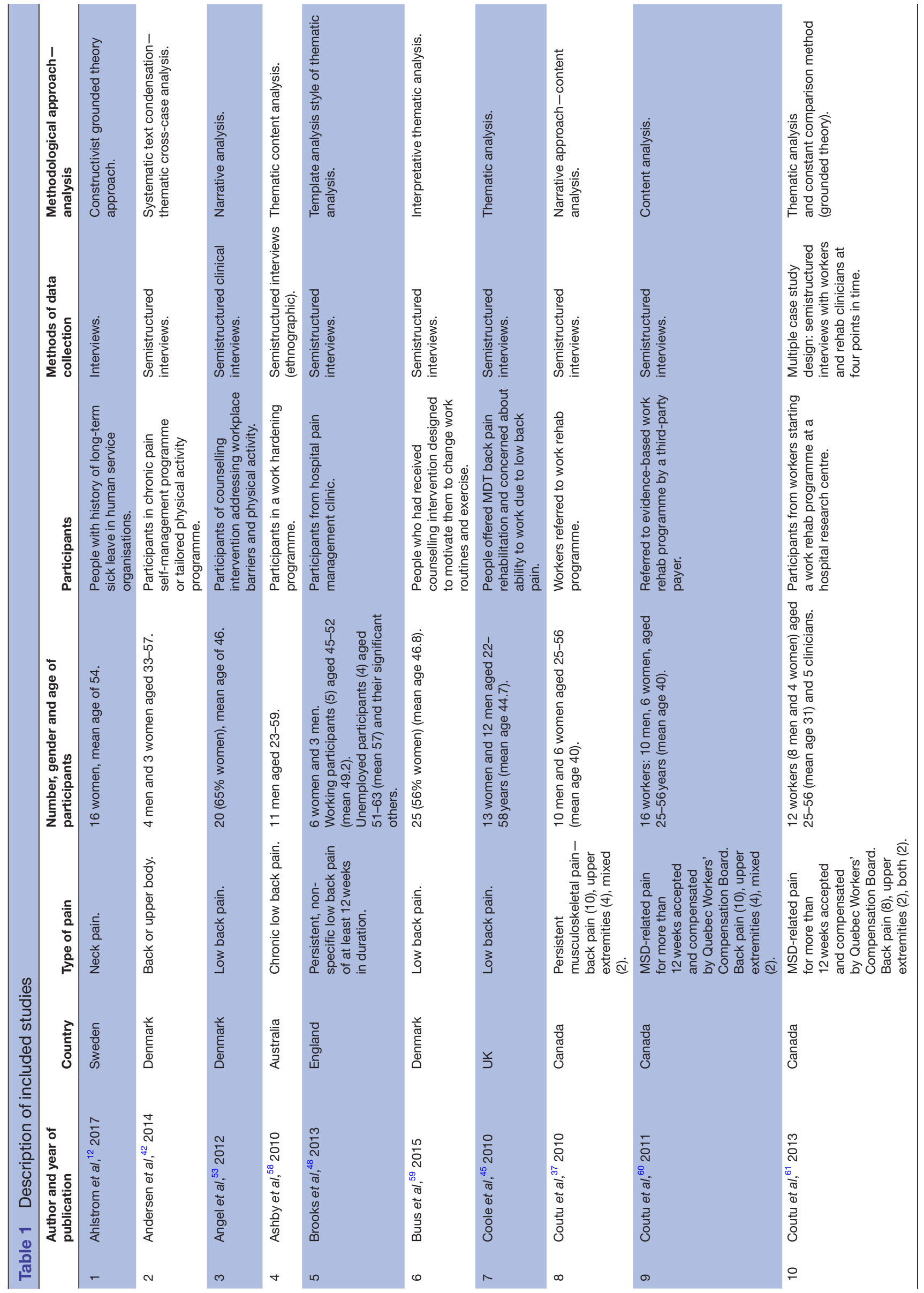

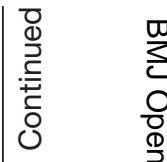




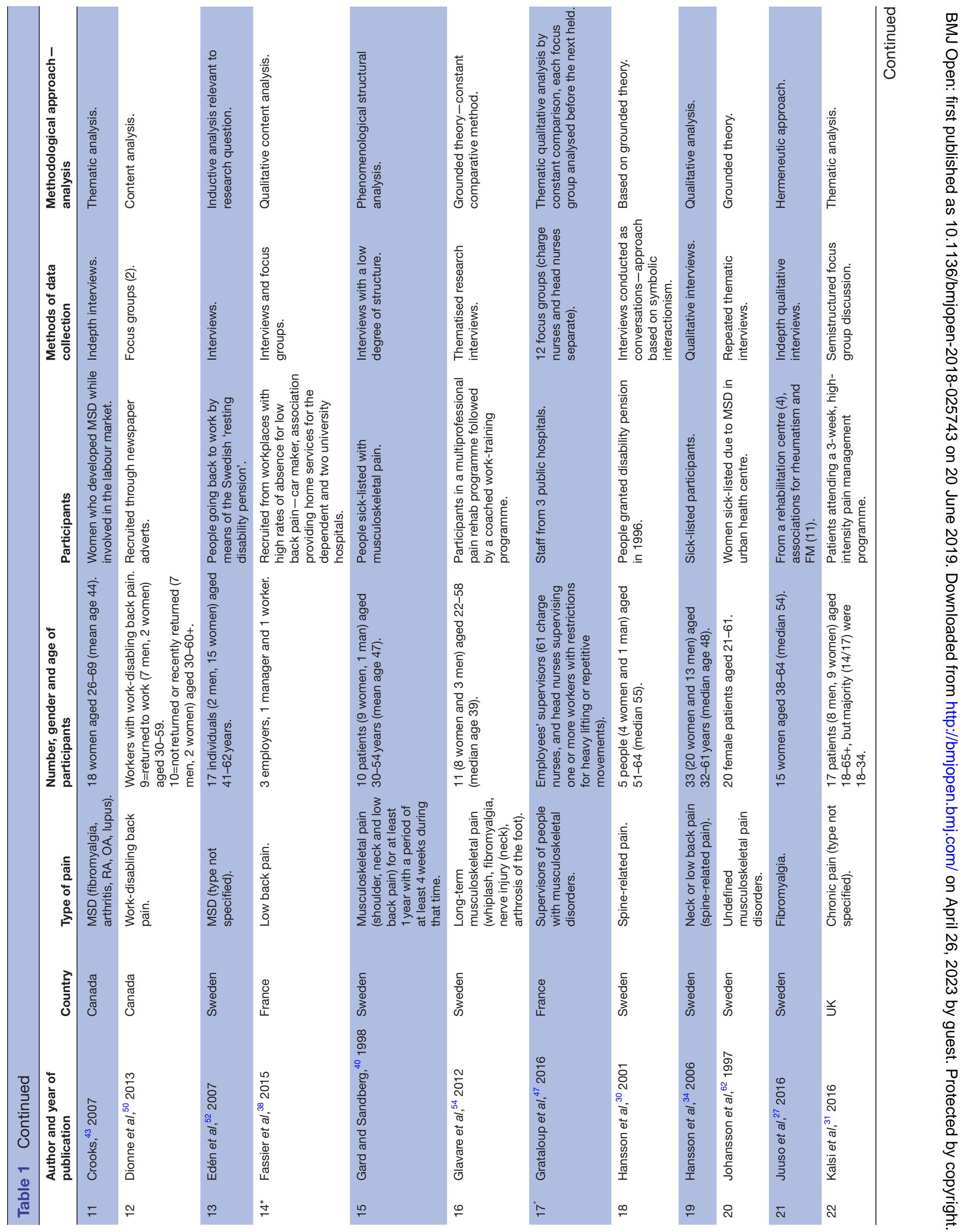




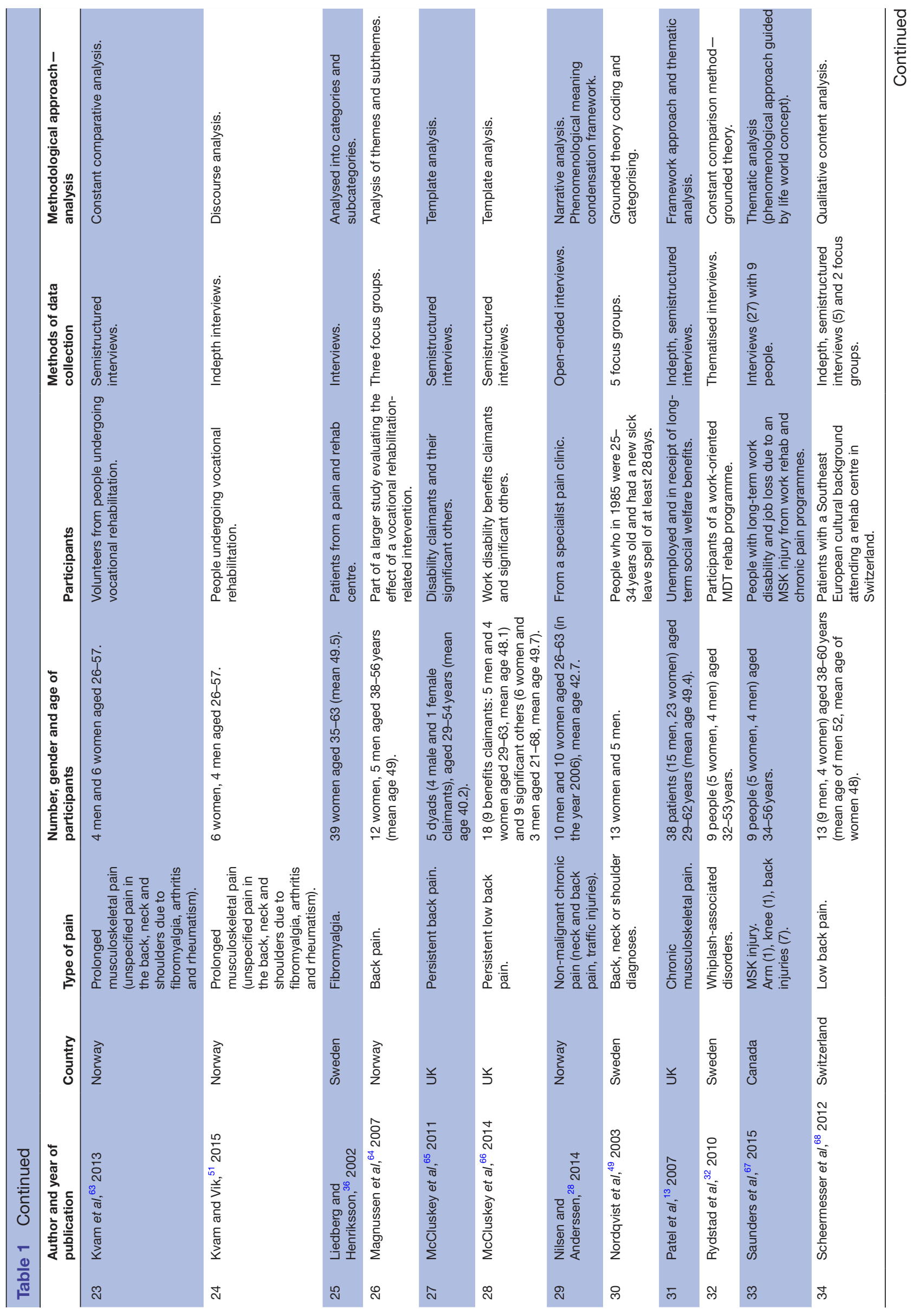

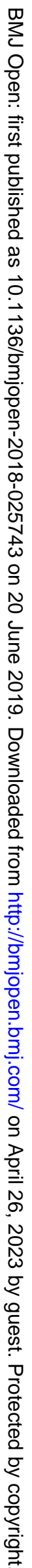




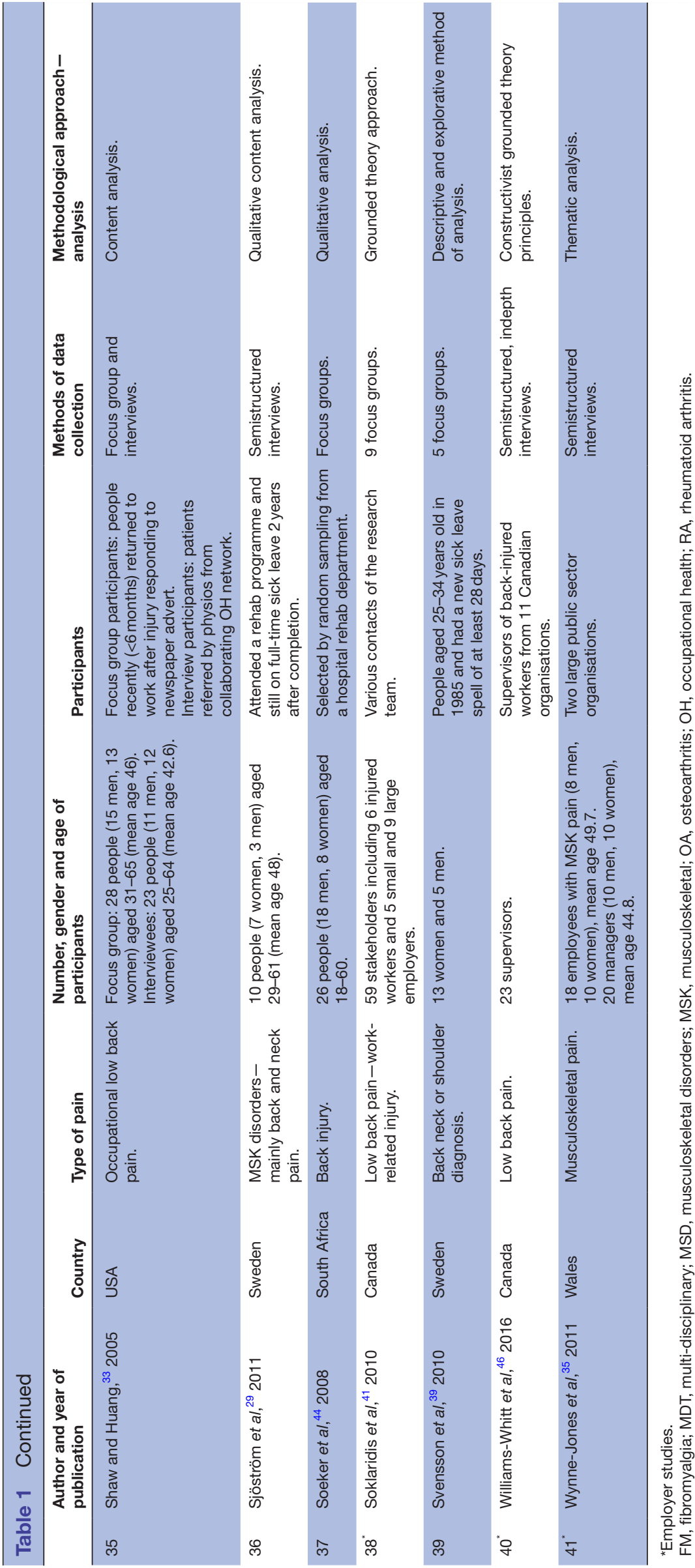

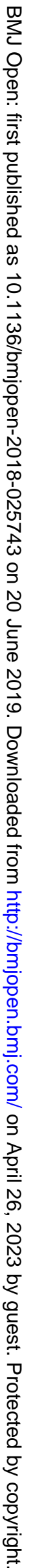




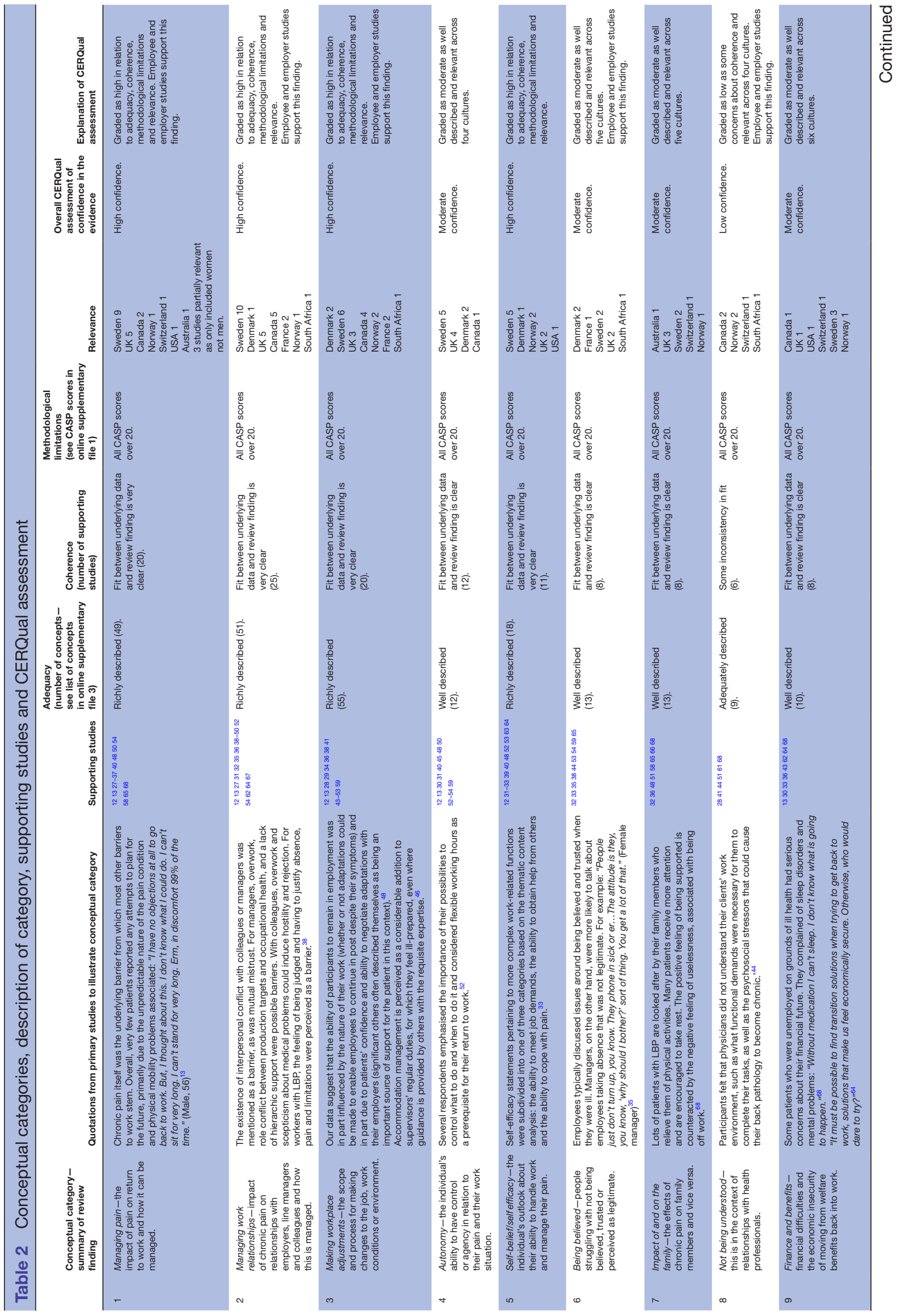




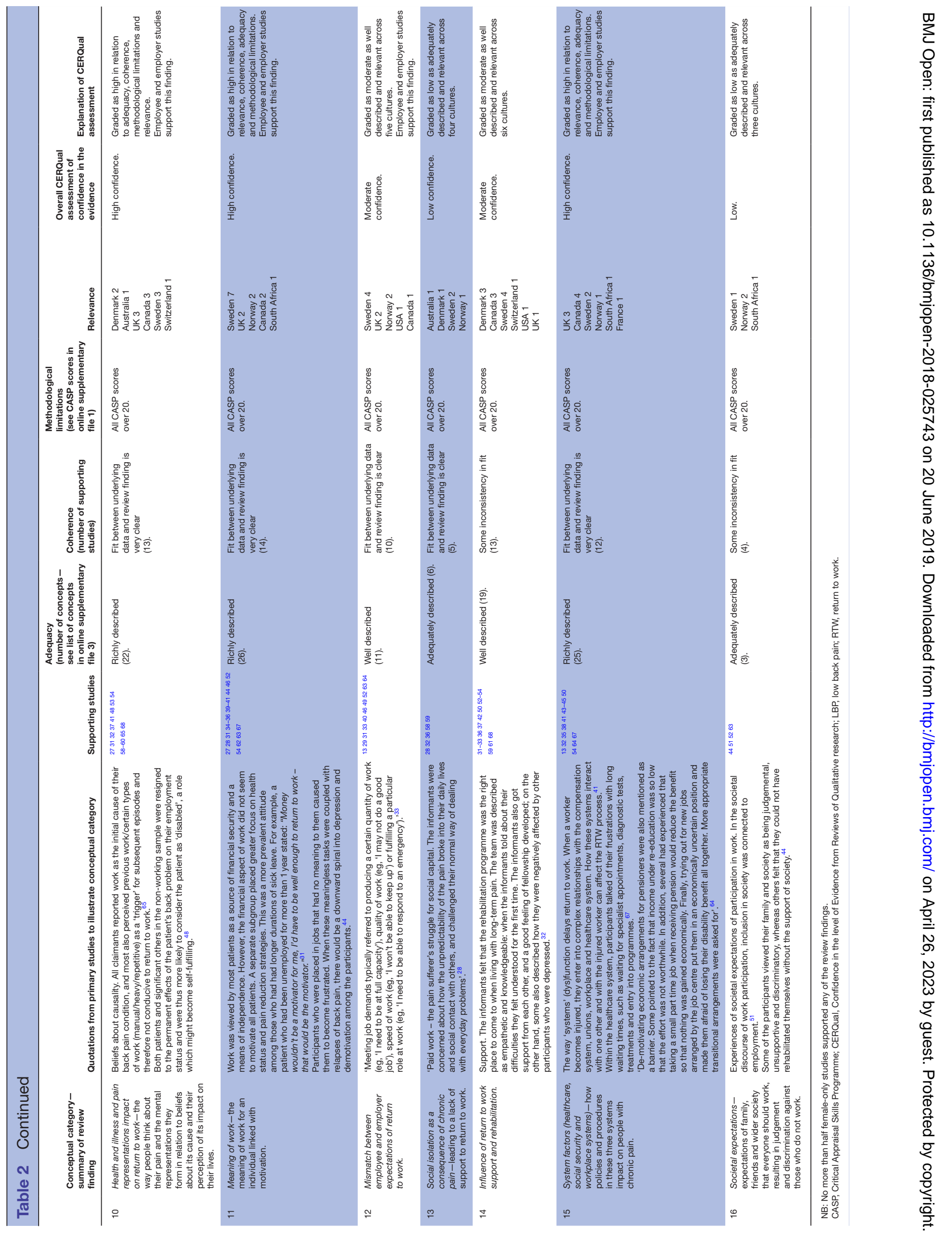


and the way they are influenced by other factors appear to be central to negotiating a successful return to work. The scope for managing pain and making adjustments in the workplace can be influenced by the quality of the relationship an individual has with their employer and/ or line manager and what is feasible within a particular work setting. The remaining 13 conceptual categories are described in more detail in online supplementary file 3 . The concepts within each conceptual category are presented in online supplementary file 4.

\section{Managing pain}

Pain was seen as a major obstacle to return to work. ${ }^{27-29}$ A plethora of strategies to manage it were described, ${ }^{28-33}$ including use of sick leave. ${ }^{1234}$

They used the strategies doing a little at a time, taking continuous breaks, working slower and being aware of body posture and workloads. These strategies improved their endurance and prevented further pain. ${ }^{32}$

However, the strain of living with chronic pain meant fatigue also became a problem and low-energy levels prevented work return. ${ }^{29}$

Pain developed and became continuous, was easily provoked by work tasks and relatively resistant to pain-controlling strategies. Life became strenuous and energy was reduced. ${ }^{30}$

The impact of pain on performance $e^{35}$ and ability to attend and travel to work, ${ }^{36}$ along with the fear of pain exacerbation, ${ }^{31} 37$ were also problematic.

\section{Managing work relationships}

Interpersonal conflict and mutual mistrust can arise between people with pain and their employers and colleagues, ${ }^{38}$ and if relationships with supervisors are perceived as poor then this is demotivating in relation to work return. ${ }^{40}$ Employers with few employees expressed reservations about how far to push an employee for fear of upsetting them and causing them to be off sick for longer than necessary. ${ }^{41}$ Managers in a public sector study appeared to be walking a fine line between supporting employees, making sure colleagues were not adversely affected and that services were delivered. ${ }^{35}$ Asking for help was perceived as frustrating by people in pain, and incurred feelings of inadequacy and negativity. ${ }^{42}$ Some struggled in their interaction with employers and tended to be passive, not believing their views were listened to, or valued, which led to difficulties in sustaining work return. ${ }^{12}$ Unsympathetic employer attitude and a lack of understanding of the person's experience of pain were seen as major obstacles to work return, ${ }^{13} 31324344$ but those employers with personal experience of pain were perceived as more sympathetic and empathic. ${ }^{4546}$

One of the important employment related obstacles is the perception that employers have limited understanding about pain due to ignorance and a lack of awareness. However, patients do acknowledge that chronic pain is difficult to understand without personal experience. ${ }^{13}$

Team management responsibilities of regulating tension between colleagues were perceived as challenging when work restrictions for those with pain caused unequal work distribution, leading to a sense of injustice. ${ }^{47}$

However, if duties were reduced indefinitely, with no extra cover, workers might feel that they were burdening their colleagues. There were doubts as to how long their colleagues support might continue. ${ }^{45}$

\section{Making workplace adjustments}

An economic climate of austerity was perceived as an obstacle to work due to reduced job availability and a competitive job market. ${ }^{13}$ Reorganisations and rationalisation in the workplace meant jobs had changed and become more demanding and potentially difficult to adapt for people with a pain condition. ${ }^{36}$ In this situation, age was also seen as influential, with some feeling they were too old to retrain for a different kind of job. ${ }^{13} 44$

The type of job influenced work return decisions, with physical work being perceived as more challenging with pain $^{44} 47$ and more highly skilled work providing greater scope for flexibility and adaptation. ${ }^{48}$

Modifying work hours and days is a potential accommodation for women who develop musculoskeletal diseases, but it is only appropriate in certain work environments where such flexibility is allowed. ${ }^{43}$

People with chronic pain often felt they were not consulted or involved in the decision making about workplace redeployment or adjustment, and when desired modifications were not possible they could not return to work. ${ }^{43-45}{ }^{48}$ Managers' attitudes and efforts, ${ }^{46}$ combined with effective routine methods of regular communication of changes made to colleagues, ${ }^{49}$ were seen as ways of improving the success of workplace adjustments. Managers did not always have the resources or know what options would be available for making these adjustments and saw the planning of these accommodations as an additional demand on their time. ${ }^{46}$ Managers also felt that information about work restrictions from occupational health was not always realistic in the work setting and therefore difficult to implement. ${ }^{47}$

Many charge and head nurses complained that occupational physicians formulated unrealistic restrictions that were impossible to respect due to work organization. ${ }^{47}$

A number of workplace adjustments were felt to be helpful, including flexible hours or a reduction in hours, but were not always forthcoming. ${ }^{36} 4348$ The possibility of a gradual return to work, ${ }^{50}$ working from home or participating in a job sharing programme ${ }^{43}$ was also seen as helpful by people in chronic pain. Changes to the job itself, including physical adjustments and a reduction in 


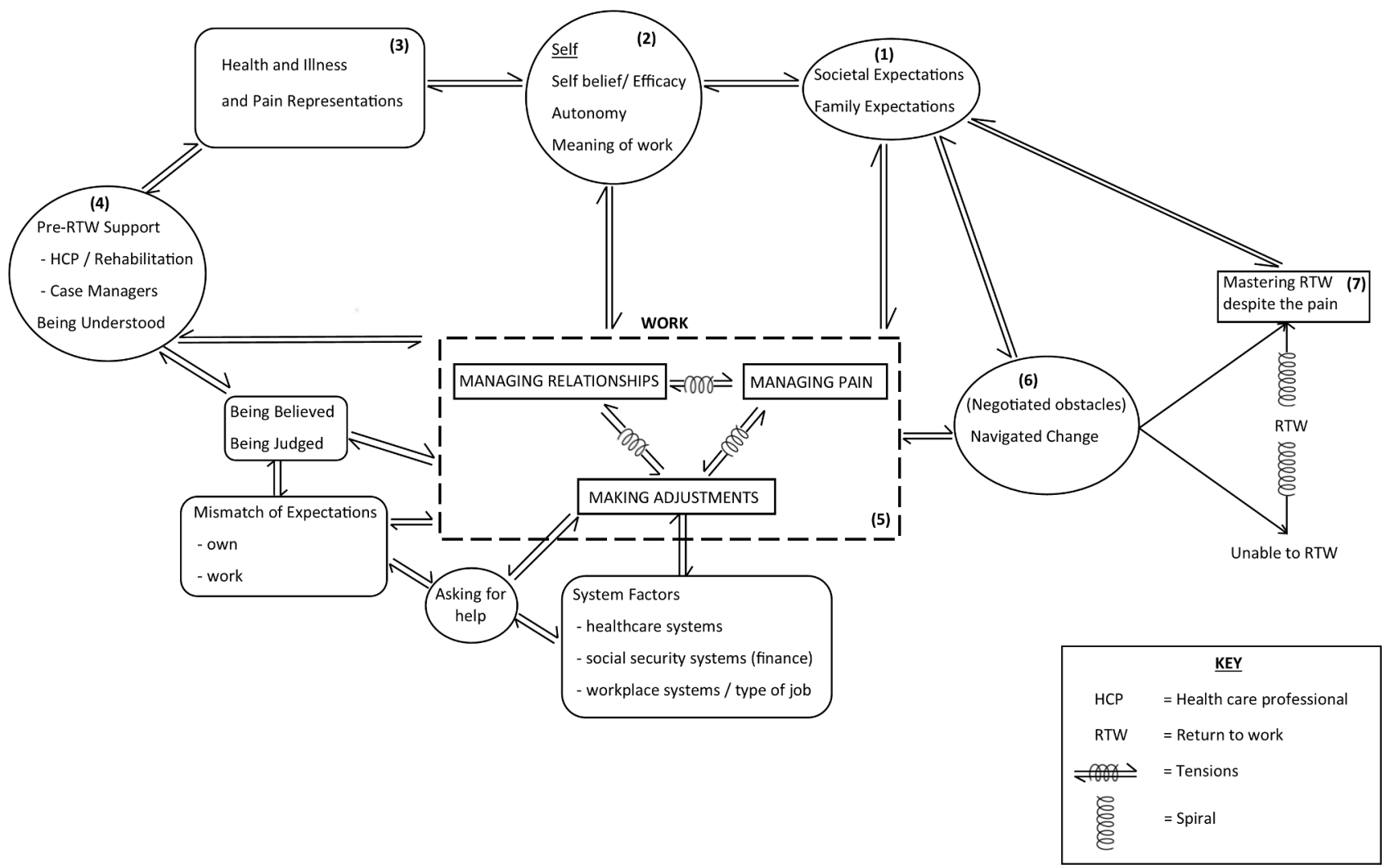

Figure 2 Conceptual model: the work of return to work. This conceptual model of return to work is explained in the text, going anticlockwise from (1) to (7).

job demands, were not always feasible, for example in a nursing, ${ }^{43}$ nursing assistant role ${ }^{36}$ or a preschool teaching role. $^{51}$

\section{Line of argument}

A line of argument was constructed by examining how the conceptual categories relate to each other. A flow diagram/conceptualmodel was then developed (figure 2).

This conceptual model of return to work is now explained, going anticlockwise from (1) to (7).

1. The underpinning foundation lies in the cultural expectation within society that people should work and contribute to the economy. Societal expectations are manifested within institutions, families and the media.

2. Societal and family expectations influence the individual's sense of self and what work means to each person. Meaning can relate to financial remuneration, rewards or survival, and meeting of social, cognitive and achievement needs or purpose in life. The individual's level of self-belief and autonomy will both play a part in how much agency and control can be exerted over pain and the work situation.

3. The way someone thinks about their pain and the mental representation they create will also influence their behaviour and the possibility of returning to work. People's perceptions of whether pain is a longterm disability could influence whether they feel able to work and thus their return to work decisions, where- as someone who has accepted the pain as part of their life and adapts may be more likely to consider return to work.

4. Some studies in the review evaluated prereturn to work support or rehabilitation programmes, and not being understood by health professionals was cited as an obstacle. In the same way, not being believed or being judged by people in the workplace was also perceived to make return to work challenging.

5 . The three key tenets of return to work are managing pain, managing work relationships and making workplace adjustments. Tension exists between these three facets and they can be influenced by a mismatch between the individual and the employer expectations, difficulties asking for help and system factors in the workplace, and health and social security systems.

6. Individuals must negotiate a wide range of obstacles and navigate change.

7. This could result in a downward spiral (and not working) at one end of a continuum through to an upward spiral of mastering return to work despite pain.

\section{DISCUSSION}

In this meta-ethnography we identified obstacles to return to work for people with chronic pain centred around three key conceptual categories: managing pain, managing work relationships in the workplace and making workplace adjustments. The dynamic relationship 
between these three closely linked categories appears to be highly influential in navigating change and overcoming obstacles individuals with chronic pain face. The ability to manage pain and negotiate workplace adjustments can be affected by the strength of relationships with employer and colleagues and what is practicable in the work environment.

The concepts of health and pain representations and the role of significant others and their thinking about pain and return to work do not appear to be highlighted by previous reviews. Another neglected area is the influence of prereturn to work support or rehabilitation. The employer perspective is missing in earlier reviews which have focused on the experience of people with chronic pain. Only five of the included studies were conducted with employers, so there is still limited research with this group despite people with pain emphasising the importance of employer attitudes and knowledge in the return to work process. ${ }^{49}$

Some studies that were included in the review appear to suggest that those people with chronic pain who manage to stay in work have different characteristics from those who are unable to do so. This is seen in part to be connected with their cognitive appraisal of their pain and whether they are able to adapt. ${ }^{3137}$ It has been proposed that in those who do not return to work, their pain representation of 'abnormal pain' becomes crystallised with their goal of pain elimination firmly intact, whereas those who returned to work began to perceive pain as 'the new normal' and something they learn to live with. ${ }^{37}$ Edén et $a \tilde{l}^{2}$ described three different adaptation patterns: the go-getter, realist and indifferent. They proposed the pessimistic and passive outlook of the latter type meant work return was less likely. Passivity in the interaction with stakeholders like the employer was found to be linked with reduced drive to return to work. ${ }^{12}$ Angel $e t a b^{53}$ and Dionne et $a \bar{l}^{0}$ also found passivity in relation to pain was not helpful when addressing workplace obstacles.

The provision of professional individualised support and coaching in the workplace was seen to be valuable in the work return process, ${ }^{54}$ and this concept supports the idea of developing work-based interventions to help people with chronic pain return to work.

When comparing findings with previous reviews that have highlighted obstacles to return to work, similarities include fears of not being able to fulfil employer expectations, not being believed by colleagues and financial concerns. ${ }^{4}$ Worries for the future, including financial and job security, were also uncovered by MacNeela $e t a l .{ }^{5}$ Strain on the family relationships, including those with partners and children, ${ }^{4}$ and gender differences regarding role as carer or breadwinner were revealed. ${ }^{5}$ Unsatisfying relationships with health professionals where people felt they were not being listened to and frustrations with limitations of medical treatment were other common features. ${ }^{5}$ Social withdrawal as a result of pain was highlighted in both of these reviews. ${ }^{45} \mathrm{~A}$ struggle for legitimacy with colleagues and stigma in the workplace was highlighted by Toye $e t a l^{7}$ and Froud $e t a l^{4}$ This review also drew attention to the system not supporting return to work due to a lack of dialogue between employers, occupational health and the health system to facilitate a gradual return with appropriate adjustments.

The collaborative team approach to conceptual analysis increased the rigour of the review. ${ }^{14}$ Independently drawing flow diagrams to illustrate the conceptual model and then coming together to amalgamate these through discussion and debate, combined with checking all concepts had been included, ensured this process was thorough.

The CERQual assessments indicated there was a high level of confidence in the findings for managing pain, managing work relationships, managing the workplace, self-belief, health and illness representations, the meaning of work and system factors. Although we have used CERQual, we found we agreed with many comments on its use by Toye $e t a l,{ }^{55}$ namely that for relevance, studies rated as partially or indirectly relevant could also contain helpful concepts. They suggest 'gravitational pull' of an idea may be important. They argue providing clear information about concepts is critical, and we have provided this in online supplementary files 3 and 4 . They also note for adequacy. 'The power of concepts to make us think, however, is not based on quantity of data included'. We agree when looking at coherence that inconsistent findings do not necessarily call the findings into question. It may be one study has developed an insight not considered in other studies. No tool can guarantee confidence in findings, and authors still need to carefully consider rigour issues.

\section{Implications}

This review identifies obstacles faced by people with chronic pain in returning to work after a period of sick leave or unemployment and can be used to inform the development of a return to work intervention. The focus of such intervention should be working collaboratively with the person who has chronic pain and the employer to explore ways of addressing managing pain, managing work relationships and making workplace adjustments. The way in which the different factors work together either to enhance or inhibit return to work is highly individual, and clinicians will need to assess what is most important for the person and employer with whom they are working. This intervention could be located in community/primary healthcare and delivered by case managers, for example, occupational therapists or occupational health nurses working alongside general practitioners. Alternatively it could be delivered by employment specialists working in employment services and trained in pain management strategies. This type of intervention would provide support tailored to the specific needs of people with chronic pain. Discussion may be needed between the employer, the employee and the case manager to enable exploration of the ways in which obstacles to return to work might be overcome. This collaborative approach 
has the potential to improve healthcare services and change workplace culture and is the kind of innovation envisioned by the UK government in their 10-year plan for people with long-term health conditions to realise their working potential. ${ }^{56}$

\section{Limitations}

It is apparent that more research is required from the employer's perspective. The five studies included in the review were from the perspective of employers working in car making, university hospitals, home care provision for disabled people in France, ${ }^{38}$ public hospitals in France, ${ }^{47}$ and National Health Service Trust and local authority in Wales. ${ }^{35}$ The Canadian study that included small and large employers did not specify the nature of the industry in which they were engaged. ${ }^{41}$

It is likely that the reviewers' backgrounds and experiences had an impact on synthesis findings. The authors came from healthcare professional and non-healthcare professional backgrounds, and these backgrounds and experiences of chronic pain provided certain lenses, which we would expect to influence our understanding.

At the time we did this work, the eMERGe Reporting Guidance for meta-ethnography ${ }^{57}$ had not been published. They were published close to the end of the peer review process for this paper.

\section{CONCLUSIONS}

The navigation of obstacles to return to work for people with chronic pain and their employers entails balancing the needs of the person with chronic pain, colleagues and the employing organisation. The influence of health and pain representations the person formulates has not been emphasised in previous reviews. Managing pain, managing relationships in the workplace and making adjustments are central to achieving a successful return to work, and these can be hard work for the person with chronic pain.

Acknowledgements We would like to thank Samantha Johnson, Academic Support Librarian (Medicine, Life Sciences and Psychology) at the University of Warwick, for her help with initial literature search and helpful guidance during the updated search process. We would like to thank Debs Smith, patient and public involvement representative, who participated in developing the research protocol as a coapplicant.

Contributors KS, RF and MU made a substantial contribution to the design of the study. MG and KS were responsible for acquisition, and MG, KS and JO-B-E were responsible for analysis and interpretation of the data. $M G$ drafted the first, subsequent and final versions, and KS, JO-B-E, RF and MU revised all versions for important intellectual content and approved the final version. All authors agree to be accountable for the accuracy and integrity of the work.

Funding This research is part of the RISE (Return to work with Individualised Supported Employment) feasibility study supported by the Versus Arthritis charity (project number 9401), and the funder has had no involvement in this paper.

Competing interests RF is chief investigator on the Versus Arthritis grant from which this project was funded. He has published multiple papers on chronic pain, some of which are referenced in this paper. RF and MU are part of an academic partnership with Serco related to return-to-work initiatives. RF and MU are directors and shareholders of Clinvivo, a university spin-out company that provides data collection services for health services research. MU was Chair of the NICE
Accreditation Advisory Committee until March 2017 for which he received a fee. $\mathrm{He}$ is chief investigator or coinvestigator on multiple previous and current research grants from the UK National Institute for Health Research and Versus Arthritis, and is a coinvestigator on grants funded by the Australian NHMRC. He is an NIHR Senior Investigator. He has received travel expenses for speaking at conferences from the professional organisations hosting the conferences. He is a coinvestigator on a study receiving support in kind from OrthoSpace. He has accepted an honorarium from CARTA. He is an editor of the NIHR journal series, and a member of the NIHR Journal Editors Group, for which he receives a fee. KS is an investigator in multiple previous and current research grants from the UK National Institute for Health Research and Versus Arthritis. She has received travel and accommodation expenses for speaking at conferences from the professional organisations hosting the conferences. She has published multiple papers on pain, some of which are referenced in this paper.

Patient consent for publication Not required.

Provenance and peer review Not commissioned; externally peer reviewed.

Data sharing statement This is a qualitative systematic review, so there are no primary research data. We have tried to include all relevant data for the qualitative systematic review in the supplementary files. Any other reasonable requests will be considered on a case-by-case basis by MG (lead author; email: M.Grant.2@ warwick.ac.uk).

Open access This is an open access article distributed in accordance with the Creative Commons Attribution 4.0 Unported (CC BY 4.0) license, which permits others to copy, redistribute, remix, transform and build upon this work for any purpose, provided the original work is properly cited, a link to the licence is given, and indication of whether changes were made. See: https://creativecommons.org/ licenses/by/4.0/.

\section{REFERENCES}

1. Blyth FM, March LM, Brnabic AJ, et al. Chronic pain in Australia: a prevalence study. Pain 2001;89:127-34.

2. Goldberg DS, McGee SJ. Pain as a global public health priority. BMC Public Health 2011;11:770.

3. Toye F, Seers K, Hannink E, et al. A mega-ethnography of eleven qualitative evidence syntheses exploring the experience of living with chronic non-malignant pain. BMC Med Res Methodol 2017;17:116.

4. Froud R, Patterson S, Eldridge S, et al. A systematic review and meta-synthesis of the impact of low back pain on people's lives. BMC Musculoskelet Disord 2014;15:50.

5. MacNeela P, Doyle C, O'Gorman D, et al. Experiences of chronic low back pain: a meta-ethnography of qualitative research. Health Psychol Rev 2015;9:63-82.

6. Johannes CB, Le TK, Zhou X, et al. The prevalence of chronic pain in United States adults: results of an Internet-based survey. J Pain 2010;11:1230-9.

7. Toye $\mathrm{F}$, Seers K, Allcock N, et al. A synthesis of qualitative research exploring the barriers to staying in work with chronic musculoskeletal pain. Disabil Rehabil 2016;38:566-72.

8. de Vries HJ, Brouwer S, Groothoff JW, et al. Staying at work with chronic nonspecific musculoskeletal pain: a qualitative study of workers' experiences. BMC Musculoskelet Disord 2011;12:126.

9. Patel AS, Farquharson R, Carroll D, et al. The impact and burden of chronic pain in the workplace: a qualitative systematic review. Pain Pract 2012;12:578-89.

10. Henriksson CM, Liedberg GM, Gerdle B. Women with fibromyalgia: work and rehabilitation. Disabil Rehabil 2005;27:685-94.

11. Wainwright $\mathrm{E}$, Wainwright $\mathrm{D}$, Keogh $\mathrm{E}$, et al. Fit for purpose? Using the fit note with patients with chronic pain: a qualitative study. $\mathrm{Br} \mathrm{J}$ Gen Pract 2011;61:e794-e800.

12. Ahlstrom L, Dellve L, Hagberg M, et al. Women with Neck Pain on Long-Term Sick Leave-Approaches Used in the Return to Work Process: A Qualitative Study. J Occup Rehabil 2017;27:92-105.

13. Patel S, Greasley K, Watson PJ. Barriers to rehabilitation and return to work for unemployed chronic pain patients: a qualitative study. Eur $J$ Pain 2007;11:831-40.

14. Toye F, Seers K, Allcock N, et al. Meta-ethnography 25 years on: challenges and insights for synthesising a large number of qualitative studies. BMC Med Res Methodol 2014;14:80.

15. Noblit GW, Hare RD. Meta-Ethnography: synthesizing qualitative studies. Newbury Park, Calif: Sage, 1988.

16. Shaw RL, Booth $A$, Sutton AJ, et al. Finding qualitative research: an evaluation of search strategies. BMC Med Res Methodol 2004;4:5. 
17. CASP. Critical appraisal skills programme qualitative assessment tool 2018. 2018 http://media.wix.com/ugd/dded87_29c5b002d99342f7 88c6ac670e49f274.pdf [Accessed 6 Jan 2018].

18. Lewin S, Booth A, Glenton C, et al. Applying GRADE-CERQual to qualitative evidence synthesis findings: introduction to the series. Implement Sci 2018;13(Suppl 1):2.

19. Lewin S, Bohren M, Rashidian A, et al. Applying GRADE-CERQual to qualitative evidence synthesis findings-paper 2: how to make an overall CERQual assessment of confidence and create a Summary of Qualitative Findings table. Implement Sci 2018;13(Suppl 1):10.

20. Glenton C, Carlsen B, Lewin S, et al. Applying GRADE-CERQual to qualitative evidence synthesis findings-paper 5: how to assess adequacy of data. Implement Sci 2018;13(Suppl 1):14.

21. Colvin CJ, Garside R, Wainwright M, et al. Applying GRADECERQual to qualitative evidence synthesis findings-paper 4: how to assess coherence. Implement Sci 2018;13(Suppl 1):13.

22. Munthe-Kaas H, Bohren MA, Glenton C, et al. Applying GRADECERQual to qualitative evidence synthesis findings-paper 3: how to assess methodological limitations. Implement Sci 2018;13(Suppl 1):9.

23. Noyes J, Booth A, Lewin S, et al. Applying GRADE-CERQual to qualitative evidence synthesis findings-paper 6 : how to assess relevance of the data. Implement Sci 2018;13(Suppl 1):4.

24. Schutz A. Concept and theory formation in the social sciences. $J$ Philos 1954;51:257-73.

25. NVivo 11 [program]: QSR International Pty Ltd. 2012.

26. Toye F, Seers K, Allcock N, et al. 'Trying to pin down jelly' - exploring intuitive processes in quality assessment for meta-ethnography. BMC Med Res Methodol 2013;13:46.

27. Juuso P, Skär L, Sundin K, et al. The Workplace Experiences of Women with Fibromyalgia. Musculoskeletal Care 2016;14:69-76.

28. Nilsen G, Anderssen N. Struggling for a normal life: work as an individual self-care management strategy among persons living with non-malignant chronic pain. Work 2014;49:123-32.

29. Sjöström R, Melin-Johansson C, Asplund R, et al. Barriers to and possibilities of returning to work after a multidisciplinary rehabilitation programme. A qualitative interview study. Work 2011;39:243-50.

30. Hansson M, Boström C, Harms-Ringdahl K. Living with spine-related pain in a changing society - a qualitative study. Disabil Rehabil 2001;23:286-95.

31. Kalsi P, Turkistani W, Sykes C, et al. "Work is a beautiful thing..." Exploring attitudes towards employment in chronic pain (CP) patients attending a pain management programme (PMP). $J$ Vocat Rehabil 2016;44:97-107.

32. Rydstad M, Schult ML, Löfgren M. Whiplash patients' experience of a multimodal rehabilitation programme and its usefulness one year later. Disabil Rehabil 2010;32:1810-8.

33. Shaw WS, Huang YH. Concerns and expectations about returning to work with low back pain: identifying themes from focus groups and semi-structured interviews. Disabil Rehabil 2005;27:1269-81.

34. Hansson M, Boström C, Harms-Ringdahl K. Sickness absence and sickness attendance-what people with neck or back pain think. Soc Sci Med 2006;62:2183-95.

35. Wynne-Jones G, Buck R, Porteous C, et al. What happens to work if you're unwell? Beliefs and attitudes of managers and employees with musculoskeletal pain in a public sector setting. J Occup Rehabil 2011;21:31-42

36. Liedberg GM, Henriksson CM. Factors of importance for work disability in women with fibromyalgia: an interview study. Arthritis Rheum 2002;47:266-74.

37. Coutu MF, Baril R, Durand MJ, et al. Transforming the meaning of pain: an important step for the return to work. Work 2010;35:209-19.

38. Fassier JB, Durand MJ, Caillard JF, et al. Results of a feasibility study: barriers and facilitators in implementing the Sherbrooke model in France. Scand J Work Environ Health 2015;41:223-33.

39. Svensson T, Müssener U, Alexanderson K. Sickness absence, social relations, and self-esteem: a qualitative study of the importance of relationships with family, workmates, and friends among persons initially long-term sickness absent due to back diagnoses. Work 2010;37:187-97.

40. Gard G, Sandberg AC. Motivating factors for return to work. Physiother Res Int 1998;3:100-8.

41. Soklaridis S, Ammendolia C, Cassidy D. Looking upstream to understand low back pain and return to work: psychosocial factors as the product of system issues. Soc Sci Med 2010;71:1557-66.

42. Andersen LN, Kohberg M, Herborg LG, et al. "Here we're all in the same boat"-a qualitative study of group based rehabilitation for sicklisted citizens with chronic pain. Scand J Psychol 2014;55:333-42.

43. Crooks VA. Women's experiences of developing musculoskeletal diseases: employment challenges and policy recommendations. Disabil Rehabil 2007;29:1107-16.
44. Soeker MS, Wegner L, Pretorius B. I'm going back to work: back injured clients' perceptions and experiences of their worker roles. Work 2008;30:161-70.

45. Coole C, Watson PJ, Drummond A. Low back pain patients experiences of work modifications; a qualitative study. BMC Musculoskelet Disord 2010;11:277.

46. Williams-Whitt K, Kristman V, Shaw WS, et al. A Model of Supervisor Decision-Making in the Accommodation of Workers with Low Back Pain. J Occup Rehabil 2016;26:366-81.

47. Grataloup M, Massardier-Pilonchéry A, Bergeret A, et al. Job Restrictions for Healthcare Workers with Musculoskeletal Disorders: Consequences from the Superior's Viewpoint. J Occup Rehabil 2016:26:245-52.

48. Brooks J, McCluskey S, King N, et al. Illness perceptions in the context of differing work participation outcomes: exploring the influence of significant others in persistent back pain. BMC Musculoskelet Disord 2013;14:48.

49. Nordqvist C, Holmqvist C, Alexanderson K. Views of laypersons on the role employers play in return to work when sick-listed. J Occup Rehabil 2003;13:11-20.

50. Dionne CE, Bourbonnais R, Frémont $\mathrm{P}$, et al. Obstacles to and facilitators of return to work after work-disabling back pain: the workers' perspective. J Occup Rehabil 2013;23:280-9.

51. Kvam L, Vik K. Discourses of participation in work among men and women in vocational rehabilitation. J Occup Sci 2015;22:345-57.

52. Edén L, Andersson HI, Ejlertsson $\mathrm{G}$, et al. Characteristics of disability pensioners returning to work: an interview study among individuals with musculoskeletal disorders. Disabil Rehabil 2007:29:1720-6.

53. Angel S, Jensen LD, Gonge BK, et al. Patients' interpretations of a counselling intervention for low back pain: a narrative analysis. Int $J$ Nurs Stud 2012;49:784-92.

54. Glavare M, Löfgren M, Schult ML. Between unemployment and employment: experience of unemployed long-term pain sufferers. Work 2012;43:475-85.

55. Toye F, Seers K, Barker K. A meta-ethnography of health-care professionals' experience of treating adults with chronic nonmalignant pain to improve the experience and quality of health care. Health Serv Deliv Res 2018;6:1-106.

56. Department of Work and Pensions DoH. Improving lives. The future of Work, Health and Disability: HMSO, 2017.

57. France $E F$, Cunningham M, Ring N, et al. Improving reporting of meta-ethnography: the eMERGe reporting guidance. BMC Med Res Methodol 2019;19:25.

58. Ashby S, Richards K, James C. The effect of fear of movement on the lives of people with chronic low back pain. Int $J$ Ther Rehabil 2010;17:232-43.

59. Buus N, Jensen LD, Maribo T, et al. Low back pain patients' beliefs about effective/ineffective constituents of a counseling intervention: a follow-up interview study. Disabil Rehabil 2015;37:936-41.

60. Coutu MF, Baril R, Durand MJ, et al. Health and illness representations of workers with a musculoskeletal disorder-related work disability during work rehabilitation: a qualitative study. J Occup Rehabil 2011;21:591-600.

61. Coutu MF, Baril R, Durand MJ, et al. Clinician-patient agreement about the work disability problem of patients having persistent pain: why it matters. J Occup Rehabil 2013;23:82-92.

62. Johansson EE, Hamberg K, Lindgren G, et al. "How could I even think of a job?"-Ambiguities in working life in a group of female patients with undefined musculoskeletal pain. Scand J Prim Health Care 1997:15:169-74.

63. Kvam L, Eide AH, Vik K. Understanding experiences of participation among men and women with chronic musculoskeletal pain in vocational rehabilitation. Work 2013;45:161-74.

64. Magnussen L, Nilsen S, Råheim M. Barriers against returning to work-as perceived by disability pensioners with back pain: a focus group based qualitative study. Disabil Rehabil 2007;29:191-7.

65. McCluskey S, Brooks J, King N, et al. The influence of 'significant others' on persistent back pain and work participation: a qualitative exploration of illness perceptions. BMC Musculoskelet Disord 2011;12:236.

66. McCluskey S, Brooks J, King N, et al. Are the treatment expectations of 'significant others' psychosocial obstacles to work participation for those with persistent low back pain? Work 2014;48:391-8

67. Saunders SL, MacEachen E, Nedelec B. Understanding and building upon effort to return to work for people with long-term disability and job loss. Work 2015;52:103-14

68. Scheermesser M, Bachmann S, Schämann A, et al. A qualitative study on the role of cultural background in patients' perspectives on rehabilitation. BMC Musculoskelet Disord 2012;13:5. 